\title{
Ocorrência de bactérias patogênicas e deteriorantes em sashimi de salmão: avaliação de histamina e de susceptibilidade a antimicrobianos
}

\author{
Occurrence of pathogenic and spoilage bacteria in salmon \\ sashimi: histamine and antimicrobial susceptibility evaluation
}

\author{
Karina Silva Cordeiro1* (1), Lygia Silva Galeno1, Cáritas de Jesus Silva Mendonça², \\ Isabel Azevedo Carvalho', Francisca Neide Costa ${ }^{1}$ \\ ${ }^{1}$ Universidade Estadual do Maranhão (UEMA), Departamento de Patologia, Laboratório de Microbiologia de \\ Alimentos e Água, Programa de Pós-Graduação em Ciência Animal, São Luís/MA - Brasil \\ ${ }^{2}$ Universidade Federal do Maranhão (UFMA), Mestrado Profissional Energia e Ambiente, São Luís/MA - Brasil
}

*Corresponding Author: Karina Silva Cordeiro, Universidade Estadual do Maranhão (UEMA), Faculdade de Medicina Veterinária, Departamento de Patologia, Laboratório de Microbiologia de Alimentos e Água, Cidade Universitária Paulo VI, s/n, Tirirical, CEP: 65055-310, São Luís/MA - Brasil, e-mail: cordeiro.k@outlook.com

Cite as: Cordeiro, K. S., Galeno, L. S., Mendonça, C. J. S., Carvalho, I. A., \& Costa, F. N. (2020). Occurrence of pathogenic and spoilage bacteria in salmon sashimi: histamine and antimicrobial susceptibility evaluation. Brazilian Journal of Food Technology, 23, e2019085. https://doi.org/10.1590/1981-6723.08519

\begin{abstract}
Resumo
O estudo das condições higiênico sanitárias de alimentos cárneos consumidos crus, como o sashimi, é necessário para definir sua qualidade e possíveis consequências para a saúde humana. Foram coletadas 60 amostras de sashimi de salmão (Salmo salar), de dez restaurantes na cidade de São Luís, Maranhão - Brasil, sendo seis de cada local. As amostras foram analisadas para contagem de coliformes a $35^{\circ} \mathrm{C}$, coliformes a $45{ }^{\circ} \mathrm{C}$ e Staphylococcus coagulase positiva e negativa, identificação da presença de Escherichia coli, Salmonella sp., Vibrio parahaemolyticus e Aeromonas spp, teste de suscetibilidade a antimicrobianos dos isolados e quantificação de histamina nas amostras. Os resultados mostraram elevadas contagens de coliformes a $35^{\circ} \mathrm{C}$ e 12 amostras com $>10^{2} \mathrm{NMP} / \mathrm{g}$ de coliformes a $45^{\circ} \mathrm{C}$, presença de $E$. coli e de Salmonella sp. em 3 amostras cada, ausência de $V$. parahaemolyticus e Staphylococcus coagulase positiva e contagem de Staphylococcus coagulase negativa entre $<20$ e 5,0×104 $\mathrm{UFC} / \mathrm{g}$, presença de Aeromonas spp. em $95 \%$ das amostras, sendo 60 isolados A. hydrophila e 6 A. caviae. Para suscetibilidade aos antimicrobianos, os isolados de $E$. coli foram sensíveis a CPM, CTX, LVX, PPT e SUT, dois resistentes a AMP; um resistente a GEN, um a AMI e um a AMC. Os isolados de Salmonella foram sensíveis a AMC, CPM, CFO, CRX, GEN, LVX e PPT, um resistente a AMl e um a AMP e SUT. Os isolados de Aeromonas foram resistentes em média a cinco dos antimicrobianos, sendo a AMP (97\%), a CRX (90,9\%) e a AMC (77,3\%), e 81,8\% foram sensíveis ao CPM. Os níveis de histamina variaram de 44,06 $\pm 0,74$ a 505,46 $\pm 8,83 \mathrm{mg} / \mathrm{kg}$, sendo 21 das amostras com níveis superiores a $100 \mathrm{mg} / \mathrm{kg}$. As amostras apresentaram condições higiênicos sanitárias insatisfatórias e riscos para a saúde pública, por identificação de bactérias patogênicas e elevadas concentrações de histamina capazes de causar intoxicação escombróide, e ainda, isolados com multirresistência aos antimicrobianos testados.
\end{abstract}

Palavras-chave: Peixe cru; Microrganismo; Escombrotoxina; Segurança alimentar; Histamina; Salmonella; Vibrio; Staphylococcus. 


\begin{abstract}
The study of the hygienic sanitary conditions of raw consumed meat foods, such the sashimi, is necessary to define their quality and possible health consequences for the population. Sixty samples of salmon sashimi (Salmo salar) were collected from ten restaurants in the city of São Luís, Maranhão, Brazil, six from each site. The samples were analyzed for coliform counts at $35{ }^{\circ} \mathrm{C}$, coliforms at $45{ }^{\circ} \mathrm{C}$ and positive and negative coagulase Staphylococcus, presence of Escherichia coli, Salmonella sp., Vibrio parahaemolyticus and Aeromonas spp, antimicrobial susceptibility test of the isolates and quantification of histamine in the samples. The results showed high counts of coliforms at $35^{\circ} \mathrm{C}$ and 12 samples with $>10^{2} \mathrm{NMP} / \mathrm{g}$ of coliforms at $45^{\circ} \mathrm{C}$, presence of $E$. coli and Salmonella in 3 samples each, absence of $V$. parahaemolyticus and coagulase positive Staphylococcus and coagulase negative Staphylococcus count between $<20$ and $5.0 \times 10^{4} \mathrm{CFU} / \mathrm{g}$, presence of Aeromonas in $95 \%$ of the samples, 60 isolates being A. hydrophila and 6 A caviae. For susceptibility to antimicrobials, $E$. coli isolates were sensitive to CPM, CTX, LVX, PPT and SUT, two isolates were resistant to AMP; one resistant to GEN, one to AMI and one to AMC. Salmonella isolates were sensitive to AMC, CPM, CFO, CRX, GEN, LVX and PPT, one resistant to AMI and one to AMP and SUT. The isolates of Aeromonas were resistant on mean to five of the antimicrobials, with AMP (97\%), CRX (90.9\%) and AMC (77.3\%), and 81.8\% were sensitive to CPM. Histamine levels ranged from $44.06 \pm 0.74$ to $505.46 \pm 8.83 \mathrm{mg} / \mathrm{kg}$, 21 of the samples with levels higher than $100 \mathrm{mg} / \mathrm{kg}$. The samples presented unsatisfactory sanitary hygiene conditions and public health risks, due to the detection of pathogenic bacteria and high concentrations of histamine capable of causing scombroid poisoning, and isolates show multiresistance to the tested antimicrobials.
\end{abstract}

Keywords: Raw fish; Microorganism; Scombrotoxin; Food safety; Histamine; Salmonella; Vibrio; Staphylococcus.

\title{
1 Introdução
}

Os peixes são alimentos de alto valor nutricional e são base de preparações como o sashimi, no qual o consumo é em forma de filés do pescado cru. Cerca 151 milhões de toneladas (t) de peixe foram utilizados para consumo humano em 2016, sendo o salmão um dos produtos mais populares no mercado mundial (Food and Agriculture Organization of the United Nations, 2018). O consumo de preparações da culinária japonesa apresentou um incremento mundial na demanda por peixe fresco (Centre for the Promotion of Imports, 2016). No Brasil, esse aumento tem sido evidenciado pelo crescente número de restaurantes e lojas especializadas (Alves et al., 2017).

A microbiota dos peixes pode refletir o seu habitat e representa a contaminação inicial do alimento, como as Enterobacteriaceae que refletem a poluição do ambiente aquático por efluentes (World Health Organization, 2012). Além de fatores relacionados: temperatura, alimentação animal e salinidade da água (Ghanbari et al., 2015) que, associados às incorretas condições de armazenamento e manipulação podem resultar na degradação da musculatura do peixe por ação enzimática e multiplicação microbiana, afetando a qualidade sanitária do alimento e segurança alimentar (Cai et al., 2015).

A criteriosa observação do fluxo de preparo de alimentos pode certificar a segurança deste. A falta de boas práticas de higiene pode resultar na contaminação por patógenos (Prado et al., 2014). Preparações como sashimi, são servidas após intensa manipulação e, portanto, sujeitas à contaminantes na ausência de procedimentos de boas práticas. A qualidade dos alimentos está associada a índices de Doenças Transmitidas por Alimentos (DTA), um problema de saúde pública com elevada ocorrência mundial, sendo igualmente necessária a vigilância em relação a patógenos emergentes (Chau et al., 2017).

No processo de deterioração bacteriana de alimentos com elevados níveis de aminas biogênicas - onde se inclui o pescado, produtos lácteos, carnes e produtos fermentados - quando degradados podem produzir substâncias tóxicas aos humanos. Como exemplo, temos a histamina, uma amina biogênica não volátil, resultante da descarboxilação enzimática da histidina, resistente ao tratamento térmico e detectável em níveis baixos no pescado recém - capturado (Shalaby, 1996; Food and Drug Administration, 2011). A intoxicação 
por histamina, também denominada escombrotoxina pode resultar do desenvolvimento de Enterobacteriaceae no pescado (Food and Agriculture Organization of the United Nations, 2012).

Os sintomas da intoxicação escombróide são dependentes da quantidade de histamina ingerida, sensibilidade individual e capacidade de desintoxicação do organismo, e ocorrem logo após o consumo (até 2h). Envolvem alterações no sistema cardiovascular, queimação na boca e garganta, dificuldade de deglutição, urticária, rubor, cefaléia, secreção nasal, broncoespasmo, taquicardia, edema, náusea, vômito e diarreia (Lohiya et al., 2015; Comas-Basté et al., 2009).

O pescado pode veicular contaminantes patogênicos e tóxicos durante a cadeia produtiva. Métodos aplicados ao controle microbiano na aquicultura, como o uso de antimicrobianos, podem resultar em multirresistência bacteriana; assim, discussões e medidas de controle para mitigar o problema são necessárias (Topp et al., 2018). Os antimicrobianos afetam os humanos e o ambiente, e devem seguir orientações específicas, bem como incluir-se testes de eficácia e sistemas de vigilância (Clinical and Laboratory Standards Institute, 2015; Agência Nacional de Vigilância Sanitária, 2016; Manyi-Loh et al., 2018).

A contaminação bacteriana de peixes, resistência a antimicrobianos e produção de histamina podem ser atribuídas a falhas na cadeia produtiva e/ou no armazenamento dos alimentos. Os objetivos deste estudo incluíram a investigação da qualidade microbiológica, com detecção e enumeração de micro-organismos, do filé de salmão na preparação de sashimi, produzido e coletado no mercado de varejo brasileiro, na cidade de São Luís - Maranhão, bem como a avaliação da resistência bacteriana a antimicrobianos dos microrganismos isolados e avaliação do alimento em estudo, como veículo de histamina.

\section{Material e métodos}

\subsection{Amostras de sashimi de salmão}

Um total de 60 amostras de sashimi (Salmo salar) foi obtido de dez restaurantes ou lojas de culinária japonesa, sendo seis amostras por local, uma a cada mês, durante seis meses, na cidade de São Luís, MA - Brasil. Todas as amostras foram adquiridas e acondicionadas na embalagem individual descartável de cada estabelecimento, colocada em caixa isotérmica com gelo reciclável e levadas para o Laboratório de Microbiologia de Alimentos e Água da Universidade Estadual do Maranhão. Cada amostra foi pesada e separada para a realização de todas as análises, somente as porções das amostras para análise de histamina foram armazenadas sob congelamento para realização posterior, de acordo com a sequência abaixo.

\subsection{Análises microbiológicas}

A realização das análises microbiológicas seguiu o método da American Public Health Association (APHA) (Vanderzant \& Splitts-Toesser, 1992). Para coliformes a $35{ }^{\circ} \mathrm{C}$ e $45^{\circ} \mathrm{C}$ a cada amostra previamente homogeneizada foi adicionada à água peptonada (Kasvi ${ }^{\circledR}$, Brasil) e preparadas diluições decimais. De cada diluição foi transferida alíquota para o caldo Lauril Sulfato Triptose - LST (Merck ${ }^{\circledR}$, Alemanha) e incubados a $35^{\circ} \mathrm{C}$ por $48 \mathrm{~h}$. Para a identificação de $E$. coli, as culturas positivas do caldo LST foram transferidas para o caldo EC (E. coli) (Himedia ${ }^{\circledR}$, USA). Seguindo semeadura em ágar Eosina Azul de Metileno (Kasvi®, Brasil) a $35^{\circ} \mathrm{C}$ por $24 \mathrm{~h}$. Colônias típicas foram submetidas a coloração de Gram (Synth, Brasil) seguindo a confirmação bioquímica, com testes INViC: indol (I), Vermelho de metila (MV), Voges-Proskauer (VP) e do citrato $(\mathrm{C})$.

Para Salmonella sp., a amostra homogeneizada foi diluída em água peptonada e incubada a $35{ }^{\circ} \mathrm{C}$ por $24 \mathrm{~h}$, a partir do crescimento nos caldos de enriquecimento foram realizadas semeadura em meio ágar Xilose Lisina Desoxicolato (Acumedia ${ }^{\circledR}, \mathrm{Neogen} \AA$, Brasil) e ágar Hektoen (Merck ${ }^{\circledR}$, Alemanha), 
submetidos a $37^{\circ} \mathrm{C}$ por $24 \mathrm{~h}$; colônias típicas seguiram a identificação bioquímica, em ágar Triplice Sugar Iron (TSI) e Lysine Iron Agar (LIA) (Isofar) e teste sorológico polivalente anti-salmonela somático e flagelar (Probac do Brasil).

Para Aeromonas spp., a amostra homogeneizada foi diluída em caldo Tripticase Soja (TSB), alíquotas foram transferidas para o ágar Vermelho de Fenol amido-ampicilina (Himedia ${ }^{\circledR}$, USA) (Palumbo et al., 1985), ágar Dextrina Ampicilina (Merck ${ }^{\circledR}$, Alemanha) (Havelaar \& Vonk, 1988), incubados a $28{ }^{\circ} \mathrm{C}$ por 24 h. Colônias típicas foram semeadas em ágar Trypticase Soy Agar (TSA), submetidas a coloração de Gram e repicadas em ágar TSI. As culturas positivas foram submetidas à prova de oxidase e catalase. Seguiram testes de acordo com a chave de identificação Aerokey II, testes de fermentação, produção de gás, motilidade, produção de indol, teste ácido de arabinose, manitol, ornitina, $\mathrm{H}_{2} \mathrm{~S}$, lisina e sacarose, reação de VogesProskauer (Carnahan et al., 1991).

Para Staphylococcus, foram feitas diluições decimais da amostra em água peptonada e alíquotas semeadas em ágar Baird-Parker (Merck ${ }^{\circledR}$, Alemanha) e submetidos a $35^{\circ} \mathrm{C}$ por $48 \mathrm{~h}$, colônias típicas foram contadas e seguiram os testes de catalase, coloração de Gram e coagulase (Probac, Brasil). Para Vibrio parahaemolyticus, a amostra homogeneizada foi diluída em água peptonada salina - $\mathrm{NaCl} 3 \%$ e diluições seriadas até $10^{-4}$, submetidos a $37^{\circ} \mathrm{C}$ por $24 \mathrm{~h}$. Coleta da película superficial do meio e semeadura em ágar Tiossulfato Citrato Bile Sacarose (Merck, Alemanha), colônias típicas foram transferidas para ágar TSI com $\mathrm{NaCl}(3 \%)$ incubados nas mesmas condições. Seguindo-se coloração de Gram, motilidade, testes bioquímicos para oxidase, arginina, lisina, lactose, sacarose, arabinose, ornitina, manose, manitol, Voges Proskauer, gelatinase e urease.

Os resultados foram interpretados segundo a Resolução da Diretoria Colegiada - RDC n ${ }^{\circ} 12$ de 02 de janeiro de 2001 - Regulamento técnico sobre os padrões microbiológicos para alimentos. Que foi atualizada recentemente para $\mathrm{RDC} \mathrm{n}^{\circ} 331$, de 23 de dezembro de 2019, que dispõe sobre os padrões microbiológicos para os alimentos e sua aplicação. E complementada pela Instrução Normativa $n^{\circ} 60$, de 23 de dezembro de 2019 - Agência Nacional de Vigilância Sanitária (Brasil, 2001, 2019a, 2019b). Onde foram acrescentadas as avaliações de $E$. coli e concentração de histamina e entram em vigor no prazo de um ano, a partir da data de publicação.

\subsection{Análise de suscetibilidade a antimicrobianos}

As análises de susceptibilidade in vitro dos isolados a antimicrobianos foi realizada de acordo com o método descrito pelo Clinical and Laboratory Standards Institute de 2015. Os antimicrobianos testados seguiram as recomendações para cada grupo de organismos e incluíram: Ampicilina (AMP) $10 \mu \mathrm{g}$, Gentamicina (GEN) $120 \mu \mathrm{g}$, Amicacina (AMI) $30 \mu \mathrm{g}$, Amoxilina-clavulanato (AMC) 20/10 $\mu \mathrm{g}$, Cefuroxima (CRX) $30 \mu \mathrm{g}$, Cefepime (CPM) $30 \mu \mathrm{g}$, Cefoxitina (CFO) $30 \mu \mathrm{g}$, Cefotaxima (CTX) $30 \mu \mathrm{g}$, Levofloxacina (LVX) $5 \mu \mathrm{g}$, Piperacilina (PPT) $100 \mu \mathrm{g}$ e Sulfa-Trimetoprim (SUT) $25 \mu \mathrm{g}$ (Laborclin, PR, Brasil).

\subsection{Análise de histamina}

A identificação e quantificação de histamina foi realizada por cromatografia líquida de alta eficiência, em equipamento HPLC proeminence (LC-10AT, SPD-M20A, CTO-20A, CBM-20A e DGU-20A $\mathrm{A}_{5 \mathrm{R}}$ ) (Shimatzu, Japão). Detector UV-Vis PhotoDiode Array Detector (DAD) a $254 \mathrm{~nm}$ e coluna de fase reversa Shim-Pack VP-ODS (250.4.6 mm, 12 nm, 4,6 $\mu \mathrm{m}, 100 \AA ̊)$, com loop de $20 \mu \mathrm{L}$. Sob gradiente de eluição e fase móvel Acetonitrila (Sigma-Aldrich, USA)/água, fluxo de $1 \mathrm{~mL} / \mathrm{min}$, pressão da bomba em $50 \mathrm{kgf} / \mathrm{cm}^{2}$ e temperatura de $40{ }^{\circ} \mathrm{C}$. Para extração, $50 \mathrm{~g}$ de cada amostra foi homogeneizada em equipamento tipo Turrax NT138 (Novatecnica, Brasil). Deste homogeneizado, pesou-se 1,0 g em balança analítica, que foi transferido para tubo de polipropileno de $50 \mathrm{~mL}$. Seguindo com a adição de 2,0 $\mathrm{mL}$ de ácido tricloroacético 
(TCA) a 5\% mol/L (Sigma-Aldrich, USA) (European Food Safety Authority, 2011) e agitou-se em vortex por $1 \mathrm{~min}$. Submeteu-se a centrífuga 420R (Hettich, Brasil) $6 \mathrm{~min}, 4{ }^{\circ} \mathrm{C}$ e $11000 \mathrm{rpm}$ e retirou-se o sobrenadante para tubos de polipropileno $15 \mathrm{~mL}$. A derivatização foi segundo Ben-Gigirey et al. (1998), com adaptações. A histamina foi identificada de acordo tempo de retenção em cromatografia e comparado a Curva Padrão, obtida a partir da diluição do padrão de Histamina $\geq 97 \% \mathrm{C}_{5} \mathrm{H}_{9} \mathrm{~N}_{3}$ (Sigma Aldrich, USA) em solução de ácido clorídrico $(\mathrm{HCl})$ 0,1 mol/L, nas concentrações 1,0; 5,0;25; 50; 100 e $150 \mathrm{mg} / \mathrm{L}$. A quantificação foi determinada a partir da medida das áreas sob os picos cromatográficos e equação da curva.

Parâmetros de estudo da curva - O método de quantificação de histamina nas amostras foi avaliado nos termos dos parâmetros analíticos: linearidade, limite de detecção e limite de quantificação (LQ). A análise das amostras foi realizada em duplicata.

\subsection{Análise estatística}

Para analisar os resultados microbiológicos, os dados foram submetidos a análise de variância ANOVA e classificação de médias e foram tratados pelo teste de Scott-Knott, no programa ASSISTAT Versão 7.7 beta, ao nível de $5 \%$ de probabilidade.

\section{Resultados e discussão}

As amostras exibiram coliformes a $35{ }^{\circ} \mathrm{C}$ sendo $65 \%$ (39) $>10^{2} \mathrm{NMP} / \mathrm{g}$ e variação de $0,4.10 \mathrm{a} \geq 2,4.10^{2} \mathrm{NMP} / \mathrm{g}$ (Tabela 1). Para coliformes a $45{ }^{\circ} \mathrm{C} 20 \%$ (12) das amostras exibiram valores $>10^{2} \mathrm{NMP} / \mathrm{g}$, e variação de $0 \mathrm{a} \geq 2,4.10^{2} \mathrm{NMP} / \mathrm{g}$ (Tabela 2). Não houve diferença estatística significativa entre as médias. Em três amostras foi detectada a presença de $E$. coli, sendo duas da mesma loja (R6). Também foi detectada presença de Salmonella sp. em três amostras de lojas diferentes.

Tabela 1. Determinação do Número Mais Provável (NMP/g) de coliformes a $35^{\circ} \mathrm{C}$ em amostras de sashimi de salmão de dez restaurantes, 2017.

\begin{tabular}{|c|c|c|c|c|c|c|c|c|}
\hline $\begin{array}{l}\text { Local de } \\
\text { Coleta }\end{array}$ & $\mathbf{r A}$ & rB & rC & rD & $\mathbf{r E}$ & $\mathbf{r F}$ & \multicolumn{2}{|c|}{ Médiab/Desvio Padrão } \\
\hline $\mathrm{R} 1$ & $2,4 \times 10^{2}$ & $2,4 \times 10^{2}$ & $1,1 \times 10^{2}$ & $2,4 \times 10^{2}$ & $4,6 \times 10$ & $2,4 \times 10^{2}$ & $1,9 \times 10^{2} \mathrm{a}$ & $\pm 0,9 \times 10^{2}$ \\
\hline $\mathrm{R} 2$ & $2,4 \times 10^{2}$ & $0,5 \times 10$ & $2,4 \times 10^{2}$ & $2,1 \times 10$ & $2,1 \times 10$ & $2,4 \times 10^{2}$ & $1,3 \times 10^{2 \mathrm{a}}$ & $\pm 1,2 \times 10^{2}$ \\
\hline $\mathrm{R} 3$ & $2,4 \times 10^{2}$ & $1,1 \times 10^{2}$ & $0,9 \times 10$ & $2,4 \times 10^{2}$ & $4,6 \times 10$ & $2,4 \times 10^{2}$ & $1,5 \times 10^{2 \mathrm{a}}$ & $\pm 1,0 \times 10^{2}$ \\
\hline $\mathrm{R} 4$ & $2,4 \times 10^{2}$ & $2,4 \times 10^{2}$ & $4,6 \times 10$ & $2,4 \times 10^{2}$ & $1,5 \times 10$ & $0,4 \times 10$ & $1,3 \times 10^{2} \mathrm{a}$ & $\pm 1,2 \times 10^{2}$ \\
\hline R5 & $2,4 \times 10^{2}$ & $2,4 \times 10^{2}$ & $2,4 \times 10^{2}$ & $2,4 \times 10^{2}$ & $1,1 \times 10^{2}$ & $2,4 \times 10$ & $1,8 \times 10^{2 \mathrm{a}}$ & $\pm 0,9 \times 10^{2}$ \\
\hline R6 & $2,4 \times 10^{2}$ & $2,4 \times 10^{2}$ & $0,9 \times 10$ & $1,1 \times 10^{2}$ & $1,1 \times 10^{2}$ & $2,4 \times 10^{2}$ & $1,6 \times 10^{2 a}$ & $\pm 1,0 \times 10^{2}$ \\
\hline R7 & $1,5 \times 10$ & $2,4 \times 10^{2}$ & $1,5 \times 10$ & $2,4 \times 10^{2}$ & $4,6 \times 10$ & $2,4 \times 10^{2}$ & $1,3 \times 10^{2 \mathrm{a}}$ & $\pm 1,2 \times 10^{2}$ \\
\hline $\mathrm{R} 8$ & $4,6 \times 10$ & $2,4 \times 10^{2}$ & $0,9 \times 10$ & $2,4 \times 10^{2}$ & $2,4 \times 10^{2}$ & $4,6 \times 10$ & $1,4 \times 10^{2} \mathrm{a}$ & $\pm 1,1 \times 10^{2}$ \\
\hline R9 & $2,4 \times 10^{2}$ & $2,4 \times 10^{2}$ & $2,4 \times 10^{2}$ & $2,4 \times 10^{2}$ & $2,4 \times 10^{2}$ & $1,1 \times 10^{2}$ & $2,2 \times 10^{2 \mathrm{a}}$ & $\pm 0,5 \times 10^{2}$ \\
\hline $\mathrm{R} 10$ & $0,9 \times 10$ & $2,4 \times 10^{2}$ & $4,6 \times 10$ & $2,4 \times 10^{2}$ & $1,1 \times 10^{2}$ & $2,4 \times 10^{2}$ & $1,5 \times 10^{2 \mathrm{a}}$ & $\pm 1,1 \times 10^{2}$ \\
\hline
\end{tabular}

Coeficiente de Variação de coliformes a $35^{\circ} \mathrm{C}(\mathrm{CV})=26,54 \%$. ${ }^{\mathrm{a}}$ Médias seguidas por letras iguais não apresentam diferença estatística. ${ }^{\mathrm{b}} \mathrm{Os}$ dados foram transformados para $\log \mathrm{X}+1$ para entrar na normalidade. r: repetição. $\mathrm{R}$ : restaurante. 
Tabela 2. Determinação do Número Mais Provável (NMP/g) de coliformes a $45^{\circ} \mathrm{C}$ em amostras de sashimi de salmão em dez restaurantes, 2017.

\begin{tabular}{|c|c|c|c|c|c|c|c|c|}
\hline $\begin{array}{l}\text { Local de } \\
\text { Coleta }\end{array}$ & $\mathbf{r A}$ & $\mathbf{r B}$ & $\mathrm{rC}$ & rD & $\mathbf{r E}$ & $\mathbf{r F}$ & \multicolumn{2}{|c|}{ Médiab/Desvio Padrão } \\
\hline $\mathrm{R} 1$ & $2,4 \times 10^{2}$ & $0,4 \times 10^{2}$ & $0,9 \times 10$ & $0,5 \times 10^{2}$ & $0,5 \times 10^{2}$ & $0,1 \times 10^{2}$ & $0,6 \times 10^{2 a}$ & $\pm 0,9 \times 10^{2}$ \\
\hline $\mathrm{R} 2$ & $2,4 \times 10^{2}$ & $0,2 \times 10$ & $0,2 \times 10$ & $0,4 \times 10$ & $0,2 \times 10$ & $0,2 \times 10$ & $0,4 \times 10^{2} \mathrm{a}$ & $\pm 1,0 \times 10^{2}$ \\
\hline $\mathrm{R} 3$ & $2,4 \times 10^{2}$ & $0,6 \times 10^{2}$ & $0,2 \times 10$ & $2,4 \times 10^{2}$ & $0,2 \times 10^{2}$ & $0,2 \times 10^{2}$ & $0,9 \times 10^{2 \mathrm{a}}$ & $\pm 1,2 \times 10^{2}$ \\
\hline $\mathrm{R} 4$ & $2,4 \times 10^{2}$ & $0,1 \times 10$ & $0,1 \times 10$ & $0,2 \times 10$ & $0,2 \times 10$ & $0,4 \times 10$ & $0,4 \times 10^{2} \mathrm{a}$ & $\pm 1,0 \times 10^{2}$ \\
\hline R5 & $2,4 \times 10^{2}$ & $0,5 \times 10^{2}$ & $0,9 \times 10$ & $0,1 \times 10^{2}$ & $0,7 \times 10$ & $0,9 \times 10$ & $0,5 \times 10^{2 \mathrm{a}}$ & $\pm 0,9 \times 10^{2}$ \\
\hline R6 & $2,4 \times 10^{2}$ & $0,2 \times 10$ & $0,1 \times 10$ & $1,1 \times 10^{2}$ & $1,1 \times 10^{2}$ & $0,2 \times 10^{2}$ & $0,8 \times 10^{2} \mathrm{a}$ & $\pm 0,9 \times 10^{2}$ \\
\hline R7 & $0,1 \times 10^{2}$ & $0,2 \times 10$ & 0,0 & $0,2 \times 10^{2}$ & $0,5 \times 10^{2}$ & $2,4 \times 10^{2}$ & $0,5 \times 10^{2 a}$ & $\pm 0,9 \times 10^{2}$ \\
\hline $\mathrm{R} 8$ & $0,4 \times 10^{2}$ & $0,4 \times 10$ & $0,1 \times 10$ & $0,5 \times 10^{2}$ & $0,5 \times 10^{2}$ & $0,2 \times 10$ & $0,2 \times 10^{2 a}$ & $\pm 0,2 \times 10^{2}$ \\
\hline R9 & $2,4 \times 10^{2}$ & $0,1 \times 10^{2}$ & $0,1 \times 10$ & $0,2 \times 10^{2}$ & $1,1 \times 10^{2}$ & $0,1 \times 10$ & $0,6 \times 10^{2} \mathrm{a}$ & $\pm 0,9 \times 10^{2}$ \\
\hline $\mathrm{R} 10$ & $0,2 \times 10^{2}$ & $0,1 \times 10$ & $0,2 \times 10$ & $0,1 \times 10$ & $0,5 \times 10^{2}$ & $0,4 \times 10$ & $0,9 \times 10^{2 \mathrm{a}}$ & $\pm 0,2 \times 10^{2}$ \\
\hline
\end{tabular}

Coeficiente de Variação de coliformes a $45^{\circ} \mathrm{C}(\mathrm{CV})=49,53 \%$. ${ }^{\mathrm{a}}$ Médias seguidas por letras iguais não apresentam diferença estatística. ${ }^{\mathrm{b}} \mathrm{Os}$ dados foram transformados para $\log \mathrm{X}+1$ para entrar na normalidade. r: repetição. $\mathrm{R}$ : restaurante.

A elevada contagem de coliformes a $35{ }^{\circ} \mathrm{C}$ não implica necessariamente um risco para saúde, mas apresenta precária qualidade sanitária do alimento. E considerando a presença de E. coli em amostras com baixas contagens de coliformes a $45{ }^{\circ} \mathrm{C}$, deve se ter atenção redobrada aos critérios de boas práticas de manipulação dos alimentos. Sendo, as contagens acima de $10^{2} \mathrm{NMP} / \mathrm{g}$ para coliformes a $45^{\circ} \mathrm{C}$, consideradas como em condições sanitárias insatisfatórias, de acordo com a RDC n. ${ }^{\circ}$ 12/01 (Brasil, 2001).

A qualidade e infraestrutura do local de preparo de alimentos pode ter impacto na segurança e qualidade microbiológica dos alimentos produzidos. Surtos causados por bactérias patogênicas têm gerado maior atenção à segurança dos alimentos, especialmente quanto ao tamanho da população do patógeno. Pois, mesmo um pequeno número de patógenos podem resultar em contaminação cruzada, alimentos inseguros e causar surtos de origem alimentar (Liang et al., 2016).

Uma vez que a infecção por Salmonella é possível com apenas dez cepas viáveis (Liang et al., 2016) é necessária atenção redobrada a higiene e sanitização de ambientes. Lee et al. (2014) relataram 298 surtos de 2001 a 2009 em um banco de dados do Centers for Disease Control and Prevention (2012) associado a preparações da culinária japonesa; dos quais, 211 foram devidos a enterite por Salmonella.

Com semelhantes resultados, Nespolo et al. (2012) ratificaram que o congelamento é a melhor prática de armazenamento para salmão e Chau etal. (2017) destacou a necessidade de criteriosa escolha dos fornecedores, para garantia de alimento seguro (Trafialek et al., 2017). Segundo Luiz et al. (2017), estratégias como a aplicação de boas práticas não têm sido suficientes, havendo necessidade de novas tecnologias sanitizantes na indústria de pescado, assim como, a busca por produtos bactericidas com ação sobre microrganismos patogênicos emergentes e que sejam seguros sob o ponto de vista químico. Igualmente é importante a avaliação da viabilidade de medidas para eliminação eficiente de Salmonella nos alimentos, considerando a matriz alimentar, a forma de consumo dos alimentos e parâmetros econômicos.

A população encontrada de Staphylococcus coagulase negativa variou de $<20$ a 5,0x $10^{4} \mathrm{UFC} / \mathrm{g}$, não tendo sido identificado Staphylococcus coagulase positiva (Tabela 3). Não houve diferença estatística significativa entre as médias por local de coleta. A presença de Staphylococcus, Salmonella sp. e E. coli indicam a condição higiênica geral do alimento, e as duas últimas a contaminação por fezes ou efluentes (Vieira, 2003).Raramente os Staphylococcus coagulase negativa causam doenças em indivíduos sadios, mas são 
considerados micro-organismos oportunistas em hospedeiros imunologicamente imaturos ou comprometidos (Medeiros et al., 2008), sendo de elevada importância garantir o mínimo de contaminação por Staphylococcus coagulase negativo dos alimentos (Becker et al., 2014; Liang et al., 2016).

Tabela 3. Unidades Formadoras de Colônia (UFC/g) de Staphylococcus coagulase negativa em amostras de sashimi de salmão de dez restaurantes, 2017.

\begin{tabular}{|c|c|c|c|c|c|c|c|c|}
\hline $\begin{array}{l}\text { Local de } \\
\text { Coleta }\end{array}$ & $\mathbf{r A}$ & $\mathbf{r B}$ & rC & rD & $\mathbf{r E}$ & $\mathbf{r F}$ & \multicolumn{2}{|c|}{ Médiab/Desvio Padrão } \\
\hline $\mathrm{R} 1$ & $1,7 \times 10^{4}$ & $<20$ & $2,1 \times 10^{3}$ & $<20$ & $<20$ & $<20$ & $3,2 \times 10^{3}$ a & $\pm 7,0 \times 10^{3}$ \\
\hline $\mathrm{R} 2$ & $2,0 \times 10^{4}$ & $<20$ & $2,4 \times 10^{2}$ & $4,3 \times 10^{3}$ & $4,3 \times 10^{3}$ & $<20$ & $4,6 \times 10^{3} \mathrm{a}$ & $\pm 7,0 \times 10^{3}$ \\
\hline R3 & $8,0 \times 10^{3}$ & $<20$ & $1,2 \times 10^{3}$ & $5,0 \times 10^{4}$ & $<20$ & $<20$ & $1,0 \times 10^{4} \mathrm{a}$ & $\pm 20 \times 10^{3}$ \\
\hline $\mathrm{R} 4$ & $8,0 \times 10^{3}$ & $<20$ & $4,6 \times 10^{3}$ & $<20$ & $4,2 \times 10^{2}$ & $<20$ & $2,2 \times 10^{3} \mathrm{a}$ & $\pm 3,0 . \times 10^{3}$ \\
\hline R5 & $3,2 \times 10^{3}$ & $<20$ & $<20$ & $6,3 \times 10^{2}$ & $<20$ & $2,1 \times 10^{2}$ & $0,7 \times 10^{3}$ a & $\pm 1,0 \times 10^{3}$ \\
\hline R6 & $3,1 \times 10^{3}$ & $<20$ & $1,1 \times 10^{3}$ & $6,0 \times 10^{3}$ & $7,3 \times 10^{3}$ & $<20$ & $3,0 \times 10^{3}$ a & $\pm 3,0 \times 10^{3}$ \\
\hline R7 & $6,0 \times 10^{3}$ & $<20$ & $6,4 \times 10^{3}$ & $1,3 \times 10^{3}$ & $2,2 \times 10^{3}$ & $<20$ & $3,0 \times 10^{3}$ a & $\pm 3,0 \times 10^{3}$ \\
\hline $\mathrm{R} 8$ & $1,4 \times 10^{3}$ & $<20$ & $6,1 \times 10^{2}$ & $3,0 \times 10^{2}$ & $<20$ & $<20$ & $0,4 \times 10^{3} \mathrm{a}$ & $\pm 0,5 \times 10^{3}$ \\
\hline R9 & $1,8 \times 10^{3}$ & $<20$ & $1,8 \times 10^{3}$ & $7,5 \times 10^{2}$ & $<20$ & $<20$ & $0,7 \times 10^{3}$ a & $\pm 1,0 \times 10^{3}$ \\
\hline $\mathrm{R} 10$ & $5,0 \times 10^{3}$ & $<20$ & $<20$ & $6,0 . \times 10^{3}$ & $7,0 \times 10^{3}$ & $<20$ & $3,0 \times 10^{3} \mathrm{a}$ & $\pm 3,0 \times 10^{3}$ \\
\hline
\end{tabular}

Coeficiente de Variação $(\mathrm{CV})=48,77 \%$. ${ }^{\mathrm{a}}$ Médias seguidas por letras iguais não apresentam diferença estatística. ${ }^{\mathrm{b}} \mathrm{Os}$ dados foram transformados para $\log \mathrm{X}+1$ para entrar na normalidade. r: repetição. R: restaurante.

Foi identificada Aeromonas spp. em 95\% (57) das amostras analisadas, obtendo-se 66 isolados, destes 91\% (60) A. hydrophila e 9\% (6) A. caviae (Tabela 4). Não foi identificado V. parahaemolyticus nas amostras de sashimi de salmão.

Tabela 4. Espécies de bactérias do gênero Aeromonas isoladas de amostras de sashimi de restaurantes, 2017.

\begin{tabular}{cccccccccccc}
\hline \multicolumn{10}{c}{ Restaurantes } \\
\hline Espécies & R1 & R2 & R3 & R4 & R5 & R6 & R7 & R8 & R9 & R10 & Total \\
\hline A. hydrophila & 5 & 7 & 6 & 6 & 5 & 7 & 6 & 7 & 5 & 6 & 60 \\
\hline A. caviae & 0 & 0 & 1 & 0 & 3 & 1 & 0 & 0 & 1 & 0 & 6 \\
\hline Total & 5 & 7 & 7 & 6 & 8 & 8 & 6 & 7 & 6 & 6 & 66 \\
\hline
\end{tabular}

No Brasil, não há critério de pesquisa para Aeromonas em produtos cárneos consumidos crus (Brasil, 2001), mas sua presença em alimentos constitui um perigo para a saúde humana (Nespolo et al., 2012). A contaminação ambiental e a natureza psicrotrófica das cepas (Chau et al., 2017) permitem a identificação de células viáveis em produtos sob refrigeração e podem explicar nossos resultados.

Aeromonas são patogênicas para peixes e patógenos emergentes em humanos; frequentemente presentes no esgoto bruto ou tratado, lama, águas estuarinas e praias, são tolerantes a alta salinidade (Cantas et al., 2012) e a concentrações de cloro, usadas para água potável (Ghenghesh et al., 2008), sendo a água um veículo de contaminação.

Estudos mostraram que o uso combinado de mecanismos saneantes pode ser efetivo no controle da população bacteriana. Segundo Al-Qadiri et al. (2016), o uso de água eletrolisada ácida com cloro, disponível 
de 10-20 mg/L, pode ser útil na redução da contaminação por A. hydrophila e $V$. parahaemolyticus em mexilhões e na assistência ao controle de higiene da produção, sem prejuízo à qualidade do alimento.

A. hydrophila pode ser causa de infecções fatais em humanos (Del Castillo et al., 2013), como causa de DTA, osteomielite, meningite, septicemia e infecções da pele e do trato urinário, especialmente em pacientes imunocomprometidos (Cantas et al., 2012). A. caviae, A. hydrophila e A. sobria estão associados à diarreia em crianças (Qamar et al., 2016). Portanto, é imperativo inclú́-los na avaliação microbiológica de alimentos como o pescado (Herrera et al., 2006).

A não identificação de $V$. parahaemolyticus pode ser devido a sua fragilidade a frio, que as transforma em estado não cultivável (Shi et al., 2017; Huang et al., 2018) e contrasta com sua ampla presença no ambiente marinho. No entanto, o ágar TCBS utilizado para análise é um meio seletivo para isolamento e cultivo de espécies de Vibrio sugerindo a possível presença de Vibrio sp. (Kaysner et al., 1987). 10 das 38 espécies de Vibrio sp. são patogênicas (Alaboudi et al., 2016).

Miguéis et al. (2015) verificaram cepas não patogênicas de Vibrio em sashimi e sugeriram a presença de patógenos. A carga microbiana inicial é influenciada pelo armazenamento e exposição dos alimentos, refletindo sua carga final e possível causa da DTA (Møretrø et al., 2016).

Nos testes de suscetibilidade antimicrobiana, as cepas de E. coli isoladas de três amostras de sashimi foram sensíveis a CPM, CTX, LVX, PPT e SUT, apresentando resistência a AMP, GEN, AMI e AMC. As três cepas de Salmonella sp. foram sensíveis a AMC, CPM, CFO, CRX, GEN, LVX e PPT; e apenas foi resistente a AMI, a AMP e a SUT. As cepas de Aeromonas apresentaram maior resistência aos antimicrobianos testados, sendo a AMP (97\%), a CRX (90,9\%), a AMC (77,3\%) e CFO (74,24\%). Por outro lado, 81,8\% destas cepas foram sensíveis ao CPM (Figura 1).

(A)

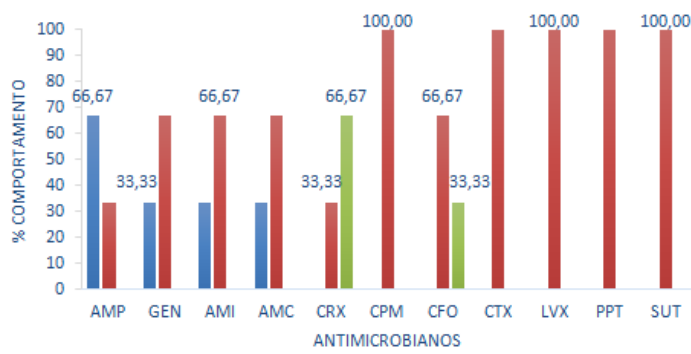

(B)

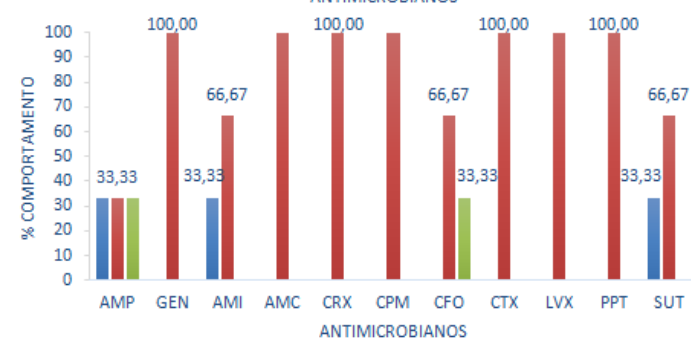

(C)

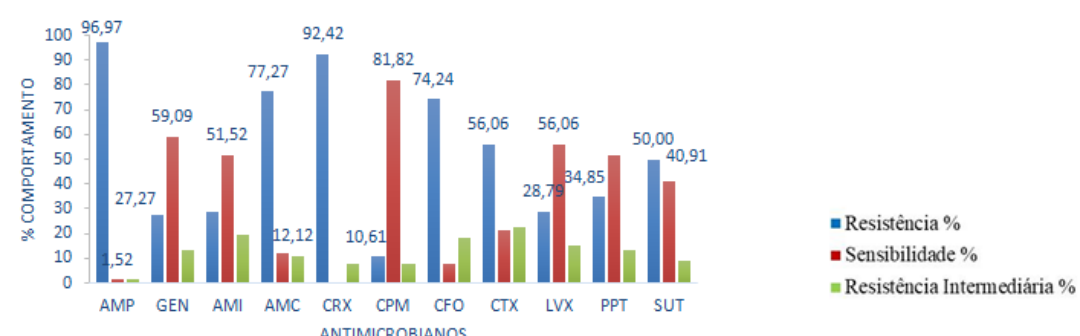

Figura 1. Resultado dos testes de suscetibilidade aos antimicrobianos de isolados de sashimi de salmão. (A) Análise de comportamento dos isolados de Escherichia coli aos antimicrobianos; (B) Análise de comportamento dos isolados de Salmonella sp. aos antimicrobianos; (C) Análise de comportamento dos isolados de Aeromonas spp. aos antimicrobianos. 
O uso indiscriminado de drogas na aquicultura pode afetar organismos e habitat, e produzir pressão seletiva, resistência a drogas e consequências negativas para o tratamento posterior de outras possíveis infecções (Marti et al., 2014). E. coli não apresenta resistência intrínseca a $\beta$-lactâmicos. No entanto, pode apresentar resistência adquirida. Carvalho et al. (2016), mostraram cepas de E. coli, originárias de caranguejos, resistentes a AMP e GEN, para além de multirresistência aos demais antimicrobianos testados.

O mecanismo de resistência aos $\beta$-lactâmicos geralmente ocorre por ação das $\beta$-lactamases, comuns entre os isolados de E. coli em alimentos de origem animal (Carvalho et al., 2016). No ambiente marinho, a família Vibrionaceae é naturalmente resistente a AMP (Radu et al., 2003); assim, a transferência de plasmídeo, que apresenta a sua resistência natural, produz bactérias resistentes aos medicamentos (Marti et al., 2014).

Para Salmonella sp. e Shigella sp., aminoglicosídeos, cefalosporinas e cefamicinas podem apresentar eficácia in vitro, mas são clinicamente ineficazes. Estes microrganismos não possuem resistência intrínseca aos $\beta$-lactâmicos. Portanto, a resistência identificada à AMP pode refletir na aquisição por interação microbiana e troca de plasmídeos (Clinical and Laboratory Standards Institute, 2015).

Resíduos de antimicrobianos em áreas de aquicultura e arredores têm sido associados à presença de genes codificados por plasmídeos, determinação de bactérias multirresistentes, transferência de resistência entre micro-organismos e manutenção do perfil bacteriano em produtos de pesca (Buschmann et al., 2012). Plasmídeos e transposons estão relacionados a isolados clínicos e ambientais de Aeromonas spp. Que apresentam resistência a antimicrobianos (Jacobs \& Chenia, 2007).

No ambiente aquático é possível o compartilhamento de plasmídeos, integrons e elementos conjugativos integrativos geneticamente relacionados com peixes, moluscos e patógenos humanos, e os peixes constituem um veículo para o carreamento de microrganismos multirresistentes (García-Aljaro et al., 2014).

$\mathrm{Na}$ aquicultura, fatores como a densidade da cultura e espécies suscetíveis a doenças estão relacionados à transmissão e difusão de infecções (Cabello et al., 2016). Para a salmonicultura chilena, foram utilizadas 557,2 toneladas de antimicrobianos em 2015 e 382,5 t em 2016, sendo 95\% administrados no mar e 4,5\% em água doce. (Chile, 2018), contribuindo para o aumento da resistência de Aeromonas spp. no ambiente (Pablos et al., 2009). Portanto, seu uso deve estar associado aos dados de suscetibilidade para a bactéria alvo.

Embora o uso racional de antimicrobianos seja o objetivo da Organização Mundial de Saúde, o uso permanece agressivo. A resistência de Aeromonas, a vários antimicrobianos encontrada nas amostras recolhidas, pode ser devida ao salmão consumido no Brasil ser originário do Chile. Em 2016, o salmão foi um dos principais produtos exportados do Chile para o Brasil, totalizando US \$ 438 milhões (Brasil, 2017).

Os valores encontrados para o índice de resistência múltipla a antibióticos (MAR) variaram de 0,18 a 1,00 e mostraram a multirresistência de $100 \%$ de isolados de Aeromonas, $33 \%$ de E. coli e $33 \%$ de Salmonella sp. Duas cepas de Aeromonas foram resistentes a nove dos onze antimicrobianos, e uma cepa apresentou resistência a todos os antimicrobianos testados (MAR $=1,00)$ (Tabela 5).

Tabela 5. Índice de Múltipla Resistência aos Antimicrobianos (MAR) de Aeromonas sp., Escherichia coli e Salmonella sp. provenientes de sashimi de salmão, 2017.

\begin{tabular}{|c|c|c|c|c|c|c|c|c|c|c|c|}
\hline \multirow{2}{*}{ (n) } & \multicolumn{11}{|c|}{ N (\%) } \\
\hline & 2 & 3 & 4 & 5 & 6 & 7 & 8 & 9 & 10 & 11 & $\mathbf{T}$ \\
\hline Aeromonas sp. & $4(6)$ & $5(7)$ & $10(15)$ & $9(17)$ & $16(24)$ & $12(18)$ & $7(11)$ & $2(3)$ & - & $1(11)$ & 66 \\
\hline E. coli & - & - & $1(33)$ & - & - & - & - & - & - & - & 3 \\
\hline Salmonella sp. & $1(33)$ & - & - & - & - & - & - & - & - & - & 3 \\
\hline Índice MAR & 0,18 & 0,27 & 0,36 & 0,45 & 0,54 & 0,63 & 0,72 & 0,81 & - & 1,00 & - \\
\hline
\end{tabular}


Alterações genéticas em micro-organismos aquáticos e transferência horizontal são mecanismos decisivos para a multirresistência antimicrobiana e podem ser consequência do transporte de seus resíduos pelas correntes marinhas (Buschmann et al., 2012; Yano et al., 2014). Por exemplo, fatores de virulência, como citotoxinas geneticamente similares à toxina E. coli shiga, foram exibidos em plasmídeos de Aeromonas (Pablos et al., 2009). A multirresistência com índices $>0,2$ e $<0,2$ está associada ao uso ocasional de antimicrobianos (Adeleke \& Omafuvbe, 2011).

Da mesma forma, Dib et al. (2018), em análises de sardinha e camarão, observaram uma elevada percentagem de multirresistência dos isolados de $E$. coli, e a associaram a um alto grau de manipulação de peixes no ambiente de vendas. Além disso, é importante enfatizar que E. coli e outras Enterobacteriaceae são produtores de histamina em peixes marinhos, envolvidos com intoxicação alimentar escombróides.

Na produção de salmão chileno, a administração de antimicrobianos é inadequada e resulta em alterações na biodiversidade de sedimentos e águas no entorno de sistemas abertos de aquicultura (Watts et al., 2017). Portanto, medidas de uso controlado desses compostos são necessárias para minimizar esses riscos sem comprometer a aquicultura.

Os resultados sugerem a aquisição de matéria-prima contaminada, armazenamento inadequado e contaminação cruzada nos procedimentos de produção. A sensibilidade reduzida às drogas testadas indica uma diminuição na gama de terapêuticas de possíveis infecções transmitidas por esses alimentos. É vital que a população tenha acesso às informações, que os surtos sejam notificados, que as agências fiscalizadoras deem atenção à prevenção de DTA e ao controle e inspeção de pescado.

Elevados índices de multirresistência, de micro-organismos presentes em alimentos, mostram-se um risco a saúde humana. É importante que investigações em alimentos, especialmente se consumidos crus como sashimis e sushis, assim como investigações de origem de multirresistência e suas possíveis relações com infecções e seus agravos em humanos (Smith et al., 2008; Dias et al., 2010). Sendo o controle sanitário de estabelecimentos e alimentos, através de implementação de legislação (Fortaleza, 2019) um importante passo de segurança de alimentos, visando a proteção à saúde da população.

Das 60 amostras analisadas, 47\% (28) apresentaram concentrações de histamina detectáveis pelo método, com variação de 44,06 $\pm 0,74$ a 505,46 $\pm 8,83 \mathrm{mg} / \mathrm{kg}$ e média de 208,78 mg/kg (LQ > 38,67 mg/kg). Dentre elas, 35\% (21) das amostras apresentaram concentrações $>100 \mathrm{mg} / \mathrm{kg}$ (Mercado Comum Sulamenricano, 1994; Brasil, 1997); e 10\% (6) entre 50 e $100 \mathrm{mg} / \mathrm{kg}$. Portanto 45\% (27) das amostras apresentaram concentrações acima de $50 \mathrm{mg} / \mathrm{kg}$ - limite preconizado pela Food and Drug Administration (2011), apenas uma amostra dentro do LQ apresentou concentração de 44,06 $\pm 0,74 \mathrm{mg} / \mathrm{kg}$, inferior ao limite (Tabela 6).

Tabela 6. Níveis de histamina em amostras de sashimi de salmão (Salmo salar) de dez restaurantes, 2017.

\begin{tabular}{ccccccc}
\hline \multirow{2}{*}{$\begin{array}{c}\text { Local de } \\
\text { coleta }\end{array}$} & $\mathbf{r A}$ & $\mathbf{r B}$ & $\mathbf{r C}$ & $\mathbf{r D}$ & $\mathbf{r E}$ & $\mathbf{r F}$ \\
\cline { 2 - 7 } & $\mathbf{C A} \pm \mathbf{d p}$ & $\mathbf{C A} \pm \mathbf{d p}$ & $\mathbf{C A} \pm \mathbf{d p}$ & $\mathbf{C A} \pm \mathbf{d p}$ & $\mathbf{C A} \pm \mathbf{d p}$ & $\mathbf{C A} \pm \mathbf{d p}$ \\
\hline $\mathrm{R} 1$ & $\mathrm{Nd}$ & $137,85 \pm 4,12$ & $\mathrm{Nd}$ & $\mathrm{Nd}$ & $\mathrm{Nd}$ & $\mathrm{Nd}$ \\
\hline $\mathrm{R} 2$ & $114,46 \pm 1,36$ & $\mathrm{Nd}$ & $\mathrm{Nd}$ & $394,20 \pm 22,56$ & $374,68 \pm 2,37$ & $94,06 \pm 2,60$ \\
\hline $\mathrm{R} 3$ & $147,64 \pm 2,90$ & $\mathrm{Nd}$ & $\mathrm{Nd}$ & $102,53 \pm 2,07$ & $117,76 \pm 3,07$ & $157,63 \pm 3,55$ \\
\hline $\mathrm{R} 4$ & $339,33 \pm 0,93$ & $\mathrm{Nd}$ & $\mathrm{Nd}$ & $\mathrm{Nd}$ & $\mathrm{Nd}$ & $73,52 \pm 3,62$ \\
\hline $\mathrm{R} 5$ & $456,29 \pm 3,71$ & $\mathrm{Nd}$ & $\mathrm{Nd}$ & $\mathrm{Nd}$ & $\mathrm{Nd}$ & $\mathrm{Nd}$ \\
\hline $\mathrm{R} 6$ & $\mathrm{Nd}$ & $\mathrm{Nd}$ & $\mathrm{Nd}$ & $427,53 \pm 4,26$ & $\mathrm{Nd}$ & $\mathrm{Nd}$ \\
\hline $\mathrm{R} 7$ & $90,20 \pm 1,81$ & $\mathrm{Nd}$ & $\mathrm{Nd}$ & $124,75 \pm 3,22$ & $244,09 \pm 9,27$ & $\mathrm{Nd}$ \\
\hline $\mathrm{R} 8$ & $64,05 \pm 0,91$ & $78,59 \pm 0,03$ & $\mathrm{Nd}$ & $\mathrm{Nd}$ & $274,49 \pm 3,66$ & $338,89 \pm 0,92$ \\
\hline $\mathrm{R} 9$ & $\mathrm{Nd}$ & $316,59 \pm 6,45$ & $230,39 \pm 5,01$ & $182,89 \pm 0,15$ & $52,99 \pm 1,85$ & $44,06 \pm 0,74$ \\
\hline $\mathrm{R} 10$ & $\mathrm{Nd}$ & $175,36 \pm 3,98$ & $\mathrm{Nd}$ & $505,46 \pm 8,83$ & $323,48 \pm 0,14$ & $\mathrm{Nd}$ \\
\hline $\mathrm{R}$ & & &
\end{tabular}

R: restaurantes. r: repetição. CA: concentração do analito. dp: desvio padrão. Nd: não detectável. 
As elevadas concentrações de toxinas representam riscos para a saúde de seus consumidores, constituindose alimentos veiculadores de escombrotoxina e corroboram com os níveis encontrados por Chen et al. (2010). Os níveis de histamina entre peixes e dentro de um peixe individual podem ser muito variáveis. Por este motivo a Food and Drug Administration (2011) estabeleceu o nível de $50 \mathrm{mg} / \mathrm{kg}$ ou PPM de histamina na porção edível de peixe, considerando que, se esta quantidade for encontrada, existe a possibilidade de em outras porções, a concentração ultrapassar $500 \mathrm{mg} / \mathrm{kg}$.

As bactérias histamina-positivas tais como: Proteus, Enterobacter, Serratia, Citrobacter, E. coli, Clostridium, Vibrio, Acinetobacter, Pseudomonas e Photobacterium (Tsai et al., 2004), estão associadas a condições de higiene e temperatura inadequadas de alimentos. A Food and Drug Administration (2011) recomenda o uso de temperaturas $<4,4{ }^{\circ} \mathrm{C}$ para controle de produção de histamina (escombrotoxina), considerando a ocorrência desta produção a temperaturas $>5{ }^{\circ} \mathrm{C}$ e associada à presença de Photobacterium spp. em alimentos (Kanki et al., 2004; Bjornsdottir-Butler et al., 2016).

Bactérias histamina-positivas multiplicam-se rapidamente a temperaturas superiores a $20^{\circ} \mathrm{C}$, e apresentam temperatura ótima de crescimento de aproximadamente $32{ }^{\circ} \mathrm{C}$ (Food and Drug Administration, 2011; World Health Organization, 2017). Souza et al. (2015) avaliando amostras de sushi, encontraram elevadas contagens de coliformes a $45^{\circ} \mathrm{C}$ e salientaram que o crescimento deste subgrupo reflete a reduzida aplicação de boas práticas de produção de alimentos.

Os níveis de histamina responsáveis pelos surtos de intoxicação são muito variáveis e baixos níveis eventualmente podem causar sintomas em indivíduos sensíveis. Uma dificuldade em definir uma dose tóxica específica é devida à presença de outras aminas biogênicas nos alimentos envolvidos, que podem potencializar os efeitos adversos da histamina (Comas-Basté et al., 2009).

\section{Conclusões}

As amostras de sashimi de salmão analisadas apresentaram condições higiênicas e sanitárias insatisfatórias, com a presença de elevadas contagens de coliformes a $45^{\circ} \mathrm{C}$, alta carga de Staphylococcus coagulase-negativo, identificação das bactérias patogênicas E. coli e Salmonella sp. e presença de bactérias emergentes como A. hydrophila e A. caviae.

Verificou-se multirresistência de cepas, principalmente das cepas de Aeromonas. Cepas de E. coli e Salmonella sp. isoladas apresentaram resistência principalmente ao ampicilina. E, ainda, elevadas concentrações de histamina, são capazes de causar sintomas de intoxicação escombróide e, portanto, devem ser controladas e serem consideradas como uma preocupação para a saúde dos consumidores.

\section{Agradecimentos}

Agradecemos à Fundação de Amparo à Pesquisa e ao Desenvolvimento Científico e Tecnológico do Maranhão (FAPEMA - Brasil) [edital n. ${ }^{\circ}$ 40/2015], à Coordenação de Aperfeiçoamento de Pessoal de Nível Superior (CAPES) e à Universidade Estadual do Maranhão (UEMA).

\section{Referências}

Adeleke, E. O., \& Omafuvbe, B. O. (2011). Antibiotic resistance of aerobic mesophilic bacteria isolated from poultry faeces. Research Journal of Microbiology, 6(4), 356-365. http://dx.doi.org/10.3923/jm.2011.356.365

Agência Nacional de Vigilância Sanitária - ANVISA. (2016). Antimicrobianos: Bases teóricas e uso clínico. Brasília. Recuperado em 10 de dezembro de 2019, de

http://www.anvisa.gov.br/servicosaude/controle/rede_rm/cursos/rm_controle/opas_web/modulo1/conceitos.htm

Alaboudi, A. R., Ababneh, M., Osaili, T. M., \& Al Shloul, K. (2016). Detection, identification, and prevalence of pathogenic Vibrio parahaemolyticus in fish and coastal environment in Jordan. Journal of Food Science, 81(1), M130-M134. PMid:26554333. http://dx.doi.org/10.1111/1750-3841.13151 
Al-Qadiri, H. M., Al-Holy, M. A., Shiroodi, S. G., Ovissipour, M., Govindan, B. N., Al-Alami, N., Sablani, S. S., \& Rasco, B. (2016). Effect of acidic electrolyzed water-induced bacterial inhibition and injury in live clam (Venerupis philippinarum) and mussel (Mytilus edulis). International Journal of Food Microbiology, 231, 48-53. PMid:27208583. http://dx.doi.org/10.1016/j.jifoodmicro.2016.05.012

Alves, J. C., Paiva, E. L., Milani, R. F., Bearzoti, E., Morgano, M. A., \& Diego Quintaes, K. (2017). Risk estimation to human health caused by the mercury content of Sushi and Sashimi sold in Japanese restaurants in Brasil. Journal of Environmental Science and Health. Part. B, Pesticides, Food Contaminants, and Agricultural Wastes, 52(6), 418-424. PMid:28272991. http://dx.doi.org/10.1080/03601234.2017.1293451

Becker, K., Heilmann, C., \& Peters, G. (2014). Coagulase-negative staphylococci. Clinical Microbiology Reviews, 27(4), 870926. PMid:25278577. http://dx.doi.org/10.1128/CMR.00109-13

Ben-Gigirey, B., Sousa, J. M. V. B., Villa, T. G., \& Barros-Velazquez, J. (1998). Changes in biogenic amines and microbiological analysis in Albacore (Thunnus alalunga) muscle during frozen storage. Journal of Food Protection, 61(5), 608-615. PMid:9709235. http://dx.doi.org/10.4315/0362-028X-61.5.608

Bjornsdottir-Butler, K., Sanchez, L. M., Dunlap, P. V., \& Benner Junior, R. A. (2016). Draft genome sequences of histamine- and non-histamine-producing Photobacterium strains. Genome Announcements, 4(5), e01008-e01016. PMid:27660786. http://dx.doi.org/10.1128/genomeA.01008-16

Brasil. Ministério da Agricultura e do Abastecimento. Secretaria Nacional de Defesa Agropecuária. (1997, maio 13). Regulamento técnico de identidade e qualidade de peixe fresco (inteiro e eviscerado) (Portaria ${ }^{\circ} 185$, de 13 de maio de 1997). Diário Oficial [da] República Federativa do Brasil, Brasília.

Brasil. Agência Nacional de Vigilância Sanitária - ANVISA. (2001, janeiro 10). Regulamento técnico sobre os padrões microbiológicos para alimentos (RDC n 12, de 2 de janeiro de 2001). Diário Oficial [da] República Federativa do Brasil, Brasilia.

Brasil. Ministério da Indústria, Comércio Exterior e Serviços. (2017). Brasil e Chile assinam memorando sobre Certificado de Origem Digital para agilizar comércio entre os dois países. Recuperado em 10 de dezembro de 2019, de http://www.mdic.gov.br/index.php/noticias/2880-brasil-e-chile-assinam-memorando-sobre-certificado-de-origem-digital-paraagilizar-comercio-entre-os-dois-paises

Brasil. Ministério da Saúde. (2019a, dezembro 26). Dispõe sobre os padrões microbiológicos de alimentos e sua aplicação (Resolução da Diretoria Colegiada - RDC n 331, de 23 de dezembro de 2019). Diário Oficial [da] República Federativa do Brasil, Brasília.

Brasil. Ministério da Saúde. (2019b, dezembro 26). Estabelece as listas de padrões microbiológicos para alimentos. (Instrução Normativa . IN n 60, de 23 de dezembro de 2019). Diário Oficial [da] República Federativa do Brasil, Brasília.

Buschmann, A. H., Tomova, A., Lopez, A., Maldonado, M. A., Henriquez, L. A., Ivanova, L., Moy, F., Godfrey, H. P., \& Cabello, F. C. (2012). Salmon aquaculture and antimicrobial resistance in the marine environment. PLoS One, 7(8), e42724. PMid:22905164. http://dx.doi.org/10.1371/journal.pone.0042724

Cabello, F. C., Godfrey, H. P., Buschmann, A. H., \& Dolz, H. J. (2016). Aquaculture as yet another environmental gateway to the development and globalisation of antimicrobial resistance. The Lancet. Infectious Diseases, 16(7), e127-e133. PMid:27083976. http://dx.doi.org/10.1016/S1473-3099(16)00100-6

Cai, L., Cao, A., Bai, F., \& Li, J. (2015). Effect of $\varepsilon$-polylysine in combination with alginate coating treatment on physicochemical and microbial characteristics of Japanese sea bass (Lateolabrax japonicas) during refrigerated storage. LWT - Food Science and Technology, 62(2), 1053-1059. http://dx.doi.org/10.1016/j.Iwt.2015.02.002

Cantas, L., Midtlyng, P. J., \& Sorum, H. (2012). Impact of antibiotic treatments on the expression of the R plasmid tra genes and on the host innate immune activity during pRAS1 bearing Aeromonas hydrophila infection in zebrafish (Danio rerio). BMC Microbiology, 12(37), 37. PMid:22429905. http://dx.doi.org/10.1186/1471-2180-12-37

Carnahan, A. M., Behram, S., \& Joseph, S. W. (1991). Aerokey II: A flexible key for identifying clinical Aeromonas species. Journal of Clinical Microbiology, 29(12), 2843-2849. PMid:1757558. http://dx.doi.org/10.1128/JCM.29.12.2843-2849.1991

Carvalho, M. C., Jayme, M. M., Arenazio, G. S., Araujo, F. V., Leite, S. G., \& Del Aguila, E. M. (2016). Microbiological quality assessment by PCR and its antibiotic susceptibility in mangrove crabs (Ucides cordatus) from Guanabara Bay, Rio de Janeiro, Brasil. International Journal of Microbiology, 2016, 7825031. PMid:27065187. http://dx.doi.org/10.1155/2016/7825031

Centers for Disease Control and Prevention - CDC. (2012). Foodborne illness data \& statistics. Atlanta: CDC. Recuperado em 10 de dezembro de 2019, de http://www.cdc.gov/Features/DataStatistics.html

Centre for the Promotion of Imports - CBI. Ministry od Foreign Affairs. (2016). CBI trade statistics: Fish and seafood. The Hague: CBI. Recuperado em 10 de dezembro de 2019, de https://www.cbi.eu/sites/default/files/trade-statistics-fish-seafood.pdf

Chau, M. L., Chen, S. L., Yap, M., Hartantyo, S. H. P., Chiew, P. K. T., Fernandez, C. J., Wong, W. K., Fong, R. K., Tan, W. L., Tan, B. Z. Y., Ng, Y., Aung, K. T., Mehershahi, K. S., Goh, C., Kang, J. S. L., Barkham, T., Leong, A. O. K., Gutierrez, R. A., \& $\mathrm{Ng}$, L. C. (2017). Group B Streptococcus infections caused by improper sourcing and handling of fish for raw consumption, Singapore, 2015-2016. Emerging Infectious Diseases, 23(12), 1982-1990. PMid:29148967. http://dx.doi.org/10.3201/eid2312.170596

Chen, H. C., Lee, Y. C., Lin, C. M., Hwang, D. F., \& Tsai, Y. H. (2010). Determination of histamine and bacterial isolation in marlin fillets (Makaira nigricans) implicated in a foodborne poisoning. Journal of Food Safety, 30(3), 699-710.

http://dx.doi.org/10.1111/j.1745-4565.2010.00234.x 
Chile. Servicio Nacional de Pesca y Acuicultura - SERNAPESCA. Subdirección de Acuicultura Departamento de Salud Animal. (2018). Informe sobre o uso de antimicrobianos en la salmonicultura nacional año 2018. Valparaíso, Chile.

Clinical and Laboratory Standards Institute - CLSI. (2015). Performance standards for antimicrobial susceptibility testing: Twenty-Fifth informational supplement (CLSI document, No. M100-S25). Wayne: CLSI.

Comas-Basté, O., Latorre-Moratalla, M. L., Sánchez-Pérez, S., Veciana-Nogués, M. T., \& Vidal-Carou, M. C. (2009). Histamine and other biogenic amines in food: from scombroid poisoning to histamine intolerance. In C. Proestos (Ed.), Biogenic amines. London: Intechopem. http://dx.doi.org/10.5772/intechopen.84333.

Del Castillo, C. S., Hikima, J., Jang, H. B., Nho, S. W., Jung, T. S., Wongtavatchai, J., Kondo, H., Hirono, I., Takeyama, H., \& Aoki, T. (2013). Comparative sequence analysis of a multidrug-resistant plasmid from Aeromonas hydrophila. Antimicrobial Agents and Chemotherapy, 57(1), 120-129. PMid:23070174. http://dx.doi.org/10.1128/AAC.01239-12

Dias, M. T., Santos, P. C. R. F., Oliveira, L. A. T., \& Marin, V. A. (2010). Avaliação da sensibilidade de cepas de Escherichia coli isoladas de mexilhões (Perna perna linnaeus, 1758) à antimicrobianos. Food Science and Technology, 30(2), 319-324. http://dx.doi.org/10.1590/S0101-20612010000200005

Dib, A. L., Agabou, A., Chahed, A., Kurekci, C., Moreno, E., Espigares, M., \& Espigares, E. (2018). Isolation, molecular characterization and antimicrobial resistance of enterobacteriaceae isolated from fish and seafood. Food Control, 88, 54-60. http://dx.doi.org/10.1016/j.foodcont.2018.01.005

European Food Safety Authority - EFSA. (2011). Scientific opinion on rick basead controlo f biogenic amine formation in fermented foods: EFSA Panel on Biological Hazards (BIOHAZ). EFSA Journal, 9(10), 2393 http://dx.doi.org/10.2903/j.efsa.2011.2393

Food and Agriculture Organization of the United Nations - FAO. (2012). The state of world fisheries and aquaculture 2012. Rome: FAO.

Food and Agriculture Organization of the United Nations - FAO. (2018). The states os world fisheries and aquaculture: Meeting the sustainable development goals. Rome: FAO.

Food and Drug Administration - FDA. (2011). Fish and fishery products hazards and controls guidance (4th ed., chap. 7, pp. 113-152). Washington: Office of Seafood.

Fortaleza. Secretária de Saúde. (2019, novembro 29). Requisitos higiênico-sanitários específicos para o preparo, manipulação, comercialização e distribuição de sushis e similares (Portaria $n^{\circ}$ 1405, de 29 de novembro de 2019). Diário Oficial do Município Fortaleza. Recuperado em 10 de dezembro de 2019, de https://www.legisweb.com.br/legislacao/?id=386988

García-Aljaro, C., Riera-Heredia, J., \& Blanch, A. R. (2014). Antimicrobial resistance and presence of the SXT mobile element in Vibrio spp. isolated from aquaculture facilities. The New Microbiologica, 37(3), 339-346. PMid:25180848.

Ghanbari, M., Kneifel, W., \& Domig, K. J. (2015). A new view of the fish gut microbiome: Advances from next-generation sequencing. Aquaculture, 448, 464-475. http://dx.doi.org/10.1016/j.aquaculture.2015.06.033

Ghenghesh, K. S., Ghenghesh, K. S., Ahmed, S. F., El-Khalek, R. A., Al-Gendy, A., \& Klena, J. (2008). Aeromonas: Associated infections in developing countries. Journal of Infection in Developing Countries, 2(2), 81-98. PMid:19738331. http://dx.doi.org/10.3855/T2.2.81

Havelaar, A. H., \& Vonk, M. (1988). The preparation of ampicillin dextrin agar for the enumeration of Aeromonas in water. Letters in Applied Microbiology, 7(6), 169-171. http://dx.doi.org/10.1111/j.1472-765X.1988.tb01271.x

Herrera, F. C., Santos, J. A., Otero, A., \& Garcia-Lopez, M. L. (2006). Occurrence of foodborne pathogenic bacteria in retail prepackaged portions of marine fish in Spain. Journal of Applied Microbiology, 100(3), 527-536. PMid:16478492. http://dx.doi.org/10.1111/j.1365-2672.2005.02848.x

Huang, Y. S., Hwang, C. A., Huang, L., Wu, V. C. H., \& Hsiao, H. (2018). The Risk of Vibrio parahaemolyticus infections associated with consumption of raw oysters as affected by processing and distribution conditions in Taiwan. Food Control, 86, 101-109. http://dx.doi.org/10.1016/j.foodcont.2017.10.022

Jacobs, L., \& Chenia, H. Y. (2007). Characterization of integrons and tetracycline resistance determinants in Aeromonas spp. isolated from South African aquaculture systems. International Journal of Food Microbiology, 114(3), 295-306. PMid:17173998. http://dx.doi.org/10.1016/j.ijfoodmicro.2006.09.030

Kanki, M., Yoda, T., Ishibashi, M., \& Tsukamoto, T. (2004). Photobacterium phosphoreum caused a histamine fish poisoning incident. International Journal of Food Microbiology, 92(1), 79-87. PMid:15033270. http://dx.doi.org/10.1016/j.ijfoodmicro.2003.08.019

Kaysner, C. A., Abeyta Junior, C., Wekell, M. M., Depaola Junior, A., Stott, R. F., \& Leitch, J. M. (1987). Incidence of Vibrio cholerae from estuaries of the United States West Coast. Applied and Environmental Microbiology, 53(6), 1344-1348. PMid:3606111. http://dx.doi.org/10.1128/AEM.53.6.1344-1348.1987

Lee, J. H., Hwang, J., \& Mustapha, A. (2014). Popular ethnic foods in the United States: A historical and safety perspective. Comprehensive Reviews in Food Science and Food Safety, 13(1), 2-17. http://dx.doi.org/10.1111/1541-4337.12044

Liang, W. L., Pan, I. L., Cheng, H. L., Li, T. C., Yu, P. F., \& Chan, S. W. (2016). The microbiological quality of take-away raw salmon finger sushi sold in Hong Kong. Food Control, 69, 45-50. http://dx.doi.org/10.1016/j.foodcont.2016.04.015

Lohiya, G.-S., Lohiya, S., Lohiya, S., \& Krishna, V. (2015). Scombrotoxinism: Protracted Illness following Misdiagnosis in the Emergency Department. Case Reports in Emergency Medicine, 2015, 597934. PMid:26357577.

http://dx.doi.org/10.1155/2015/597934 
Luiz, D. B., Silva, C. D. F., Campelo, S. R., Santos, V. R. V., Lima, L. K. F., Chicrala, P. C. M. S., \& Iwashita, M. K. P. (2017). Evaluation of the effectiveness of ozone as a sanitizer for fish experimentally contaminated with Salmonella sp. Brazilian Journal of Food Technology, 20(0), e2016150. http://dx.doi.org/10.1590/1981-6723.15016

Manyi-Loh, C., Mamphweli, S., Meyer, E., \& Okoh, A. (2018). Antibiotic use in agriculture and its consequential resistance in environmental sources: Potential public health implications. Molecules, 23(4), 795. PMid:29601469. http://dx.doi.org/10.3390/molecules23040795

Marti, E., Variatza, E., \& Balcazar, J. L. (2014). The role of aquatic ecosystems as reservoirs of antibiotic resistance. Trends in Microbiology, 22(1), 36-41. PMid:24289955. http://dx.doi.org/10.1016/j.tim.2013.11.001

Medeiros, E. A. S., Nouer, S. A., Silva, N. F., Grinbaum, R., Pereira, A. P. P., \& Long, J. C. (2008). Tratamento das principais infecções comunitárias e relacionadas à assistência á saúde e a profilaxia antimicrobiana em cirurgia. ATM Racional. Recuperado em 5 de janeiro de 2016, de http://www.anvisa.gov.br/servicosaude/controle/rede_rm/cursos/atm_racional/modulo3/objetivos.htm

Mercado Comum Sulamenricano - MERCoSUL. Secretaria de Defesa Agropecuária do MAARA. (1994). Recomendação $n^{\circ}$ 8/94 AR do Subgrupo de Trabalho n. 3, "Normas Técnicas" (Resolução nº 40, 1994). Diário Oficial [da] República Federativa do Brasil, Brasília.

Miguéis, S., Santos, C., Saraiva, C., \& Esteves, A. (2015). Evaluation of ready to eat sashimi in northern Portugal restaurants. Food Control, 47, 32-36. http://dx.doi.org/10.1016/j.foodcont.2014.06.025

Møretrø, T., Moen, B., Heir, E., Hansen, A. A., \& Langsrud, S. (2016). Contamination of salmon fillets and processing plants with spoilage bacteria. International Journal of Food Microbiology, 237, 98-108. PMid:27552347.

http://dx.doi.org/10.1016/j.ijfoodmicro.2016.08.016

Nespolo, N. M., Martineli, T. M., \& Rossi Junior, O. D. (2012). Microbiological quality of salmon (Salmo salar) sold in cities of the state of São Paulo, Brasil. Brazilian Journal of Microbiology, 43(4), 1393-1400. PMid:24031968. http://dx.doi.org/10.1590/S1517-83822012000400021

Pablos, M., Rodriguez-Calleja, J. M., Santos, J. A., Otero, A., \& Garcia-Lopez, M. L. (2009). Occurrence of motile Aeromonas in municipal drinking water and distribution of genes encoding virulence factors. International Journal of Food Microbiology, 135(2), 158-164. PMid:19720415. http://dx.doi.org/10.1016/j.ijfoodmicro.2009.08.020

Palumbo, S. A., Maxino, F., Williams, A. C., Buchanan, R. L., \& Thayer, D. W. (1985). Starch-ampicillin agar for the quantitative detection of Aeromonas hydrophila. Applied and Environmental Microbiology, 50(4), 1027-1030. PMid:16346899. http://dx.doi.org/10.1128/AEM.50.4.1027-1030.1985

Prado, B. G., Iwatani, J. E., Pereira, M. R., Gollucke, A. P. B., \& Toledo, L. P. (2014). Pontos críticos de controle na qualidade higiênico-sanitária do preparo de sushis e sashimis no município de São Vicente, São Paulo. Segurança Alimentar e Nutricional, 21(1), 359-372. http://dx.doi.org/10.20396/san.v21i1.1661

Qamar, F. N., Nisar, M. I., Quadri, F., Shakoor, S., Sow, S. O., Nasrin, D., Blackwelder, W. C., Wu, Y., Farag, T. Panchalingham, S., Sur, D., Qureshi, S., Faruque, A. S., Saha, D., Alonso, P. L., Breiman, R. F., Bassat, Q., Tamboura, B., Ramamurthy, T., Kanungo, S., Ahmed, S., Hossain, A., Das, S. K., Antonio, M., Hossain, M. J., Mandomando, I., Tennant, S. M., Kotloff, K. L., Levine, M. M., \& Zaidi, A. K. (2016). Aeromonas-associated diarrhea in children under 5 years: The GEMS experience. The American Journal of Tropical Medicine and Hygiene, 95(4), 774-780. PMid:27527635. http://dx.doi.org/10.4269/ajtmh.16-0321

Radu, S., Ahmad, N., Ling, F. H., \& Reezal, A. (2003). Prevalence and resistance to antibiotics for Aeromonas species from retail fish in Malaysia. International Journal of Food Microbiology, 81(3), 261-266. PMid:12485753. http://dx.doi.org/10.1016/S0168-1605(02)00228-3

Shalaby, A. R. (1996). Significance of biogenic amines to food safety and human health. Food Research International, 29(7), 675-690. http://dx.doi.org/10.1016/S0963-9969(96)00066-X

Shi, Y., Sun, R., An, D., Lu, W., Zhang, C., Wang, L., Liu, Y., \& Wang, Q. (2017). Mathematical quantification of inactivation of Vibrio parahaemolyticus on two types of surface soiled with different substrates. Food Control, 74, 1-8. http://dx.doi.org/10.1016/j.foodcont.2016.11.025

Smith, P. R., Breton, A. L., Horsberg, T. E., \& Corsin, F. (2008). Guidelines for antimicrobial use in aquaculture. In L. Guardabassi, L. B. Jensen \& H. Kruse (Eds.), Guide to antimicrobial use in animals (pp. 207-216). Oxford: WilleyBlackwell. http://dx.doi.org/10.1002/9781444302639.ch12.

Souza, T. J. F. F., Silva, J. N., Silva Filho, C. R. M., \& Santos, J. G. (2015). Microorganisms of sanitary interest in sushi. Revista do Instituto Adolfo Lutz, 4(3), 274-279.

Topp, E., Larsson, D. G. J., Miller, D. N., Van Den Eede, C., \& Virta, M. P. J. (2018). Antimicrobial resistance and the environment: assessment of advances, gaps and recommendations for agriculture, aquaculture and pharmaceutical manufacturing. FEMS Microbiology Ecology, 94(3), 1-5. PMid:29309580. http://dx.doi.org/10.1093/femsec/fix185

Trafialek, J., Drosinos, E. H., Laskowski, W., Jakubowska-Gawlik, K., Tzamalis, P., Leksawasdi, N., Surawang, S., \& Kolanowski, W. (2017). Street food vendors' hygienic practices in some Asian and EU countries: A survey. Food Control, 85, 212-222. http://dx.doi.org/10.1016/j.foodcont.2017.09.030

Tsai, Y. H., Kung, H. F., Lee, T. M., Lin, G. T., \& Hwang, D. F. (2004). Histamine related hygienic qualities and bacteria found in popular comercial scombroid fish fillets in Taiwan. Journal of Food Protection, 67(2), 407-412. PMid:14968980. http://dx.doi.org/10.4315/0362-028X-67.2.407 
Ocorrência de bactérias patogênicas e deteriorantes em sashimi de salmão: avaliação de histamina e de susceptibilidade a antimicrobianos

Cordeiro, K. S. et al.

Vanderzant, C., \& Splitt-Stoesser, D. F. (1992). Compendium of methods for the microbiological examination of foods (3rd ed.). Washington: American Public Health Association.

Vieira, R. H. S. F. (2003). Microbiologia, higiene e qualidade do pescado: Teoria e prática (1. ed.). São Paulo: Livraria Varela.

Watts, J. E. M., Schreier, H. J., Lanska, L., \& Hale, M. S. (2017). The rising tide of antimicrobial resistance in aquaculture: sources, sinks and solutions. Marine Drugs, 15(6), 1-16. PMid:28587172. http://dx.doi.org/10.3390/md15060158

World Health Organization - WHO. (2012). Animal waste, water quality and human health. London: WHO/IWA.

World Health Organization - WHO. (2017). Meeting on public health risks of histamine and other biogenic amines from fish and fishery products, joint FAO/expert report. Geneva: WHO. Recuperado em 5 de janeiro de 2016, de http://www.who.int/foodsafety/publications/histamine_risk/en/

Yano, Y., Hamano, K., Satomi, M., Tsutsui, I., Ban, M., \& Aue-Umneoy, D. (2014). Prevalence and antimicrobial susceptibility of Vibrio species related to food safety isolated from shrimp cultured at inland ponds in Thailand. Food Control, 38, 30-36. http://dx.doi.org/10.1016/j.foodcont.2013.09.019

Financiamento: Fundação de Amparo à Pesquisa e ao Desenvolvimento Científico e Tecnológico do Maranhão, edital n. ${ }^{\circ} 40 / 2015$. 